\title{
Academic Electronic Health Record Implementation: Tips for Success
}

\author{
Patricia K. Ravert \\ Brigham Young University - Provo, patricia-ravert@byu.edu \\ Kristen Whipple \\ Brigham Young University - Provo \\ Stacie Hunsaker \\ Brigham Young University - Provo
}

Follow this and additional works at: https://scholarsarchive.byu.edu/facpub

Part of the Other Nursing Commons

\section{Original Publication Citation}

Ravert, P., Whipple, K., \& Hunsaker, S. (2020, April). Academic electronic health record implementation: Tips for success. Clinical Simulation in Nursing, 41(C), 9-13.

\section{BYU ScholarsArchive Citation}

Ravert, Patricia K.; Whipple, Kristen; and Hunsaker, Stacie, "Academic Electronic Health Record Implementation: Tips for Success" (2020). Faculty Publications. 5286.

https://scholarsarchive.byu.edu/facpub/5286

This Peer-Reviewed Article is brought to you for free and open access by BYU ScholarsArchive. It has been accepted for inclusion in Faculty Publications by an authorized administrator of BYU ScholarsArchive. For more information, please contact ellen_amatangelo@byu.edu. 


\title{
Academic Electronic Health Record Implementation: Tips for Success
}

\author{
Patricia Ravert, PhD, RN, Dean and Professor*, \\ Kristen Whipple, BS, RN, Simulation Operations Supervisor, \\ Stacie Hunsaker, MS, RN, Associate Teaching Professor, Faculty Simulation \\ Coordinator
}

Brigham Young University, College of Nursing, Provo, UT, USA

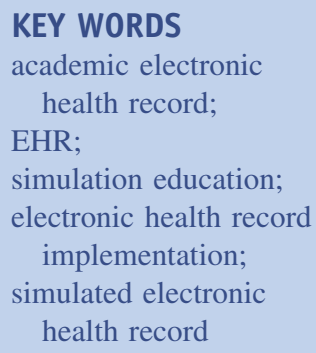

\begin{abstract}
Many nursing programs use simulation experiences to augment or replace clinical experiences. Use of an electronic health record (EHR) in the educational setting extends the realism. A task force reviewed EHR programs, selected an EHR, and created an implementation plan with successful rollout over 2 years.
\end{abstract}

\section{Cite this article:}

Ravert, P., Whipple, K., \& Hunsaker, S. (2020, April). Academic electronic health record implementation: Tips for success. Clinical Simulation in Nursing, 41(C), 9-13. https://doi.org/10.1016/ j.ecns.2019.12.008.

(C) 2020 International Nursing Association for Clinical Simulation and Learning. Published by Elsevier Inc. All rights reserved.
Many nursing programs use simulation experiences to augment or replace clinical experiences. Use of an electronic health record (EHR) may increase the reality of the simulation experience. Implementation can be challenging (Baxter \& Andrew, 2018; Borycki, Frisch, Moreau, \& Kushniruk, 2015; Chung \& Cho, 2017; Elliott, MarksMaran, \& Bach, 2018; Herbert \& Connors, 2016; Sorenson \& Campbell, 2016; Titzer \& Swenty, 2014; Warboys, Mok, \& Frith, 2014; Wilbanks, Watts, \& Epps, 2018). With an active simulation program including over 15,000 encounters by our 425 students during each academic year, the college searched for a commercial EHR for years. On the undergraduate end-of-program survey, students consistently

\footnotetext{
* Corresponding author: patricia_ravert@byu.edu (P. Ravert).
}

rated how well the nursing program prepared them regarding documentation lower (3.34 on a 4-point scale) than other areas. Occasionally, students also comment on the need to learn electronic charting such as "I think it would also be valuable to incorporate online charting at some point throughout the program. It is very important to know how to do paper charting in case you need it, but it would be nice to practice computer charting as well. Some nurses in clinical allow you to practice charting but some don't, so not everyone gets much practice through clinical experiences." We were determined to find a solution and formed a task force. After a review of EHR companies, the task force recommended the purchase of a system (MedAffinity EHR) and implemented over 2 years. As the task force assessed the process, the faculty and staff identified how and why this was a successful endeavor. Other programs may benefit from the keys to success. 


\section{Keys to Success}

\section{Establish a Working Task Force}

The college administration supported the work, established

Key Points
- Careful selection of
an electronic health
record (EHR) for
simulation use is
essential to successful
implementation.
- Successful EHR re-
quires administrative
and personnel
commitment and
resources. EHR champions and
student superusers
were essentials in im-
plementation and
training of the EHR
system.
a task force, and provided guidelines regarding costs for an EHR. The task force included simulation center personnel, an information technology (IT) staff member, and faculty (both graduate and undergraduate) who would be the main instructors for the courses using the EHR. The faculty were motivated to participate as it affected their course and student experience. The task force members had the opportunity to see what EHRs were available and gave their input into choosing the program they thought would best meet their needs.

One barrier to EHR implementation can be obtaining faculty buy-in (Kowitlawakul, Chan, Wang, \& Wang, 2014). Faculty may be reluctant to add to their own workload and are concerned about student satisfaction with the EHR and how that may affect the course ratings. Having the faculty that would be using the EHR serve on the task force helped with buy-in. Faculty that were initially hesitant to adopt EHR use in their laboratory courses were willing to implement EHR usage when they saw the available features that would meet their needs and intended usage.

\section{Task Force Work}

The task force members determined what features would be needed for course outcomes. Although Wilbanks et al. (2018) literature review was not available at the time we began our task force, their work gives suggestions of ideal properties for an educational EHR, and our task force identified many of these criteria (refer to Table). The task force members understood the educational needs, including the changing needs as students progress through the undergraduate program. The family nurse practitioner program needed a documentation program that simulated a clinic setting rather than a hospital setting. Although some educational organizations may decide to use more than one EHR system to meet the different needs of various programs, this task force agreed that the EHR would need to meet both program needs. Another important criterion that the task force wanted was that the EHR would be customizable rather than a static system. An evaluation rubric with the desired features (refer to Table) was developed to rate all EHR programs using the same criteria to assist in the analysis and comparison of different EHR programs.

Two task force members attended a conference where sales representatives from several EHR companies demonstrated their products and used the rubric for an initial evaluation. They also explored the internet to see what products were available that were not represented at the conference. This information was presented to the task force, and four companies were selected to present a demonstration to the entire task force.

EHR representatives provided 1- to 2-hour demonstrations, either onsite or remotely. The task force members rated each EHR system using the feature rubric. Discussion among task force members also occurred after each demonstration.

After demonstration and using the criteria rubric, the task force members voted on the EHR systems. There was not agreement initially, but two systems seemed to meet many of the needs. No EHR system included all the desired criteria. The task force members requested further clarification of features, and EHR representatives provided additional mini demonstrations. After much discussion, the task force developed a proposal to purchase the MedAffinity EHR. This system was customizable and had features that would work in both educational programs.

\section{Proposal for Purchase to Administrative Personnel}

The task force developed and submitted to administration a proposal with associated costs. Included in the proposal were work assignments for key implementation personnel and ongoing costs (including student charges) for use of the EHR program. This college has an endowment to financially support ongoing simulation needs, and the student costs were covered rather than charging the students an additional fee. This was extremely helpful in improving student satisfaction with the product, as there were challenges as we shifted from paper charting to electronic documentation.

\section{Personnel and Work Assignments}

\section{Overall Champion}

The overall champion was one of the task force members who was engaged in the selection and implementation process. Our overall champion is a full-time staff member in the Nursing Learning Center (NLC). As a registered nurse with years of experience and understanding of hospital-based documentation, she worked closely with the family nurse practitioner program faculty to understand the clinic-based documentation. Initially, the champion learned the system in detail and then worked with four faculty who were the course coordinators to develop chart templates and documents needed for implementation. 
Table Rubric for Evaluation of EHR Features Needed for Prelicensure Nursing and Graduate Nurse Practitioner Programs

\begin{tabular}{lrlr}
\hline Criteria for Prelicensure Nursing Program and Points Possible & Criteria for Graduate Nurse Practitioner Program and Points Possible \\
\hline Overall look of the product & 5 & Customer service \\
Customer service & 10 & Customer references \\
Customer references & 5 & Compatible with Mac and HP Computers & 10 \\
Compatible with manikins & 5 & Ease of use & 5 \\
Ease of creating patient records & 10 & Ease of deleting charts at end of semester \\
Ease of resetting at end of semester & 10 & Ability to provide feedback to students \\
Ease of grading & 5 & Remote access to program \\
Multiple student access to same patient & 10 & Cost \\
Medication bar coding & 5 & Storage needed (Server v. Cloud) \\
Cost to college & 5 & Flexibility to change templates \\
Cost to student & 10 & Medication interactions feature \\
Student remote access & 5 & Coding abilities (ICD-10, CPT, E/M) \\
Database storage-Server (0) or Cloud (10) & 10 & Supports several users simultaneously \\
Flexibility to change templates & 5 & Faculty entered data cannot be altered \\
Ease of access to R reference materials & 5 & Feature to enter laboratories and other diagnostics \\
Clinical decision support & 5 & Total points possible \\
Outpatient charting for graduate students & 10 & & \\
Total points possible & 120 &
\end{tabular}

Note. $\mathrm{EHR}=$ electronic health record.

Repeatedly, faculty and students comment that the champion (point person) made the project doable.

\section{Graduate Program Champion}

A graduate faculty member was designated as the champion/point person to assist with development of charts and forms for the graduate program. The overall champion and the graduate program champion worked to create nurse practitioner templates and set the standard of how the EHR program would be used. As more and more faculty got involved, there were additional opinions that were filtered through the two champions to maintain consistency.

\section{Course Faculty}

Faculty from courses involved in the initial implementation worked closely with the champions to convert the existing paper charts into the EHR system, determining the data to be documented and in what form or template. With the standards developed by the champions, the faculty were able to provide the information needed for each simulation for the various courses.

\section{Teaching Assistant Superusers}

The college employs nursing students as teaching assistants (TAs) and they assisted in the implementation phase. They were trained in the EHR system "superusers," assisted during the implementation. Designated times when "superusers" were available in the NLC were publicized to students so they could come for help with their EHR assignments. Using student "superusers" in the beginning of each semester was extremely helpful to assist students to access and be comfortable with EHR. After the first few weeks of the semester, the TAs were rarely called on for help as the students caught on quickly. During simulation experiences, the TAs also uploaded laboratory values and new orders in "real time" and as the student asked for laboratory results or received new orders.

\section{Information Technology Personnel}

The college employs two full-time IT staff members, with one assigned to support the EHR project. It was anticipated that he would serve as a liaison between the champion and the technology personnel of the EHR company, but in reality, this was not needed because the champion dealt directly with the EHR provider in developing the scenarios and templates. Primarily, the technical difficulties were related to the student personal laptop capabilities or setup, but the computers in the college simulation center were readily available 12 hours per day and had no technical difficulties.

\section{Tasks After Selection of EHR System}

After the task force selected MedAffinity EHR and submitted the proposal for purchase to the college administration, the available resources were reviewed, and a decision was made to purchase. The college was anxious to move quickly and implement during the coming fall semester. The initial implementation included three undergraduate semesters (about 180 students) and one graduate cohort of 15 students. The following year, the use of the EHR was implemented in the simulation laboratories of the remaining courses. Additional student training was not necessary, as the students had used the system throughout the previous year. 
Implementing the EHR in three undergraduate courses simultaneously was an ambitious undertaking. It may have been much easier to implement initially in only one course and then add EHR documentation to subsequent courses as those students progressed through the program. However, this approach would have not allowed all students to be introduced to an EHR before graduation. Our task force determined the need to learn electronic documentation was great enough that it was important to implement quickly. Overall, this approach was challenging but successful.

\section{Scenario and Template Building}

Part of the contract with the EHR provider (MedAffinity) was for building of forms to support our existing simulation experiences. We gathered and sent all our materials, scenarios, and chart information for 33 skills and simulation experiences to MedAffinity. They developed forms within the EHR over approximately four months. MedAffinity was very accommodating and input many more scenarios that we expected.

During this time, we discovered the EHR contained a way for nurse practitioners to track their assessments but was not appropriate for a hospital-based registered nurse. Although MedAffinity had prepared templates for charts and background material, there were no templates to chart nursing assessments or interventions as the original MedAffinity documents were more suited to a clinic rather than to a hospital setting. The overall champion and faculty members teaching the fundamental and medical-surgical courses with input from the assessment course faculty member began the summer break task of creating templates for charting nursing assessment and interventions (approximately 375 hours between two people). Because our fundamentals and medical-surgical laboratory courses teach skills in context of a scenario, it was necessary to have templates suitable for students to document all the care given to their "patients" in those laboratories.

Our assessment course, as the first course students take in the nursing program, had different needs. Rather than using point-and-click templates as were used in the other courses, the assessment course faculty member wanted students to learn the vocabulary of assessment. Early assignments were mainly free text and progressed throughout the semester until assignments were pointand-click, like a hospital EHR, at the end. This served to introduce students gradually to EHR use and build their skills until they were prepared to document in their Fundamentals semester.

\section{Graduate Program Templates}

After initial template development, the graduate champion began working with the overall champion to develop and revise templates for the family nurse practitioner program. The graduate champion worked with other graduate faculty members to refine the templates. Like the undergraduate program, graduate documentation is taught in a stepwise fashion to enable students to learn the necessary documentation of a nurse practitioner assessment.

\section{User (Student) Information for MedAffinity}

Rather than develop a new numbering or code system, we chose to use the system already used at the university (net ID as user name and university identification number as password). We learned to be consistent in how the data are configured and sent with new cohorts of students.

\section{Grading Rubrics}

The course coordinators worked with the champion to develop customized rubrics for each course and laboratory so that all instructors could quickly evaluate the charting completed by students. After review of the student documentation, the feedback from the instructors was given to the students so they could see where improvement was needed in their charting. Each course has several graded pass-offs that include documentation that is graded as well.

\section{Training}

\section{Faculty Training}

The initial training was an overview for interested faculty shortly after selection of the MedAffinity EHR. All faculty were invited to the initial training, although those teaching in the NLC were expected to attend as they would use the EHR beginning the next semester. Detailed training occurred for the champions, IT staff, NLC faculty, and instructors. Approximately two weeks before the fall semester started, there were additional training sessions for NLC faculty and instructors. The MedAffinity EHR system is quite easy to use and with the work over the summer, the system was ready for implementation in fall semester.

\section{Establish and Train Superusers}

The student TAs were trained as superusers. The TAs were required to attend a superuser clinic and quickly learned the EHR system. Superusers were available to sit with students in the NLC computer laboratory and assist them while they learned to navigate the system.

\section{User (Student) Training}

Undergraduate students were trained during their courses (both didactic and simulation experiences). Initially, we began a 15-minute introduction in the first nursing course (undergraduate and graduate programs) by walking them through logging into the EHR program. We found this was not enough and changed to a 50-minute session during new student orientation where students accessed charts and received tips for success. Users (students) charted either on computers in the laboratory during simulation experiences or on their personal computers while completing homework assignments. The superusers (TAs) were available at the beginning of each semester. The overall 
champion, graduate champion, and superusers trouble shoot for students; if additional help is needed, the EHR company has a 17-hour support line that was rarely used.

For the graduate students, the overall champion attended their class and taught them how to use the EHR. The champion was available during "real-time" exercises in class. There was adequate EHR training in class, so the graduate students were comfortable with the program as they used it during timed clinical assessments.

\section{Maintenance of the EHR}

Once the implementation was complete throughout the undergraduate and the graduate program, the college transitioned to a maintenance mode. Maintenance includes updating and creating new templates and scenarios as needed. Each semester, updated user information is sent to MedAffinity. We continue to provide superusers at the beginning of each semester, although the amount of time they are available has been decreased as it was observed they were not being used as much as when we first implemented the EHR. The overall champion (or whichever term you decide to use) supports students and faculty in the continued use of the EHR, which includes troubleshooting and access issues. The champion regularly interfaces with MedAffinity.

\section{Summary}

Overall, the implementation has been tremendously successful. After implementation of the EHR, on the end-ofprogram survey, students rated how well the nursing program prepared them regarding documentation higher than before implementation of the EHR system; preimplementation was 3.34 and postimplementation was 3.76 on a 4-point scale. On course evaluations, students commented that charting in the EHR helped them understand what to chart, and the practice helped them to be ready for "real life." Each semester, one laboratory still requires paper charting so that if there is computer downtime in the health care setting, the students will have exposure to paper documentation. Students, both undergraduate and graduate, express gratitude for their opportunity to learn documentation through an EHR in the NLC. Success occurred through efforts from all involved, particularly the EHR task force, the champions, and the course faculty.

\section{Acknowledgments}

Special thanks to Colleen Tingey, Lacey Eden, Gaye Ray, Dr. Deborah Himes, and Dr. Beth Luthy who tirelessly shared their expertise for successful implementation of the electronic health record in our Nursing Learning Center.

\section{References}

Baxter, P. M., \& Andrew, L. A. (2018). Successful implementation of an academic electronic health record into the curriculum of an associate degree nursing program. Nursing Education Perspectives, 39(4), 250-252. https://doi.org/10.1097/01.NEP.0000000000000255.

Borycki, E. M., Frisch, N., Moreau, J., \& Kushniruk, A. W. (2015). Integration of electronic health records into nursing education: issues, challenges and limitations. Studies in Health Technology and Informatics, 208, 88-92. https://doi.org/10.3233/978-1-61499-488-6-88.

Chung, J., \& Cho, I. (2017). The need for academic electronic health record systems in nurse education. Nurse Education Today, 54, 83-88. https://doi.org/10.1016/j.nedt.2017.04.018.

Elliott, K., Marks-Maran, D., \& Bach, R. (2018). Teaching student nurses how to use electronic patient records through simulation: A case study. Nurse Education in Practice, 30, 7-12.

Herbert, V. M., \& Connors, H. (2016). Integrating an academic electronic health record: Challenges and success strategies. CIN Computers, Informatics, Nursing, 34(8), 345-354.

Kowitlawakul, Y., Chan, S. W. C., Wang, L., \& Wang, W. (2014). Exploring faculty perceptions towards electronic health records for nursing education. International Nursing Review, 61(4), 499-506. https://doi.org/10.1111/inr.12141.

Sorenson, J., \& Campbell, L. (2016). Curricular path to value: Integrating an academic electronic health record. Journal of Nursing Education, 55(12), 716-719.

Titzer, J. L., \& Swenty, C. F. (2014). Integrating an academic health record in a nursing program: Creating a sense of urgency and sustaining change. Nurse Educator, 39(5), 212-213. https://doi.org/10.1097/NNE. 0000000000000064.

Warboys, I., Mok, W. Y., \& Frith, K. H. (2014). Electronic medical records in clinical teaching. Nurse Educator, 39(6), 298-301.

Wilbanks, B. A., Watts, P. I., \& Epps, C. A. (2018). Electronic health records in simulation education: Literature review and synthesis. Simulation in Healthcare: Journal of the Society for Simulation in Healthcare, 13(4), 261-267. 